Independent Journal of Management \& Production (IJM\&P) ISSN: 2236-269X DOI: $10.14807 /$ ijmp.v3i2.47

v. 3, n. 2, July - December 2012

\title{
BARRIERS TO THE IMPLEMENTATION OF QUALITY MANAGEMENT SYSTEM IN MEDIA ORGANIZATIONS IN PAKISTAN: AN EMPIRICAL STUDY.
}

\author{
Muhammad Naveed Anwar \\ Wide Angle studio (pvt) Ltd. - Pakistan \\ E-mail: mnanwar1998@gmail.com
}

Submission: 10/12/2012

Accept: 20/12/2012

\section{ABSTRACT}

Quality management system has played pivotal role in establishing organizational functions and processes in the very right perspective of a very well knitted system of documentation, training and implementation. Media organizations are so close in their very existence and social structure and they are more than needed to stream line their processes as their impact on social life is significant and considerable. This study encompasses the top news channels in Pakistan and recorded the views of their top management with respect to their feelings pertaining to QMS. This study is very first one of its kinds in Pakistan and it is hoped that it may open more doors for future research avenues in this very area.

Key-words: Quality management system, media, organization

\section{INTRODUCTION}

Quality management is a foremost managerial revolution spanning 20th century (LILLRANK, 2003). It is methodically and systematically framed on definite approach to control production deficiencies, concentrated responsiveness towards consumers and stressed collaborative controlling initiatives. There were lots of fair efforts to imitate it accomplishment in corporate governance, utilities and information system based setups (JURAN \& GODFREY, 1999).

A different set of realities come across those who seem participated in the induction and introduction of quality management performance packages; they even experienced reluctance in people attitude with reference to QMS at different levels. The primary lack of top management support is considered as the fundamental reason 
Independent Journal of Management \& Production (IJM\&P) ISSN: 2236-269X DOI: 10.14807/ijmp.v3i2.47

v. 3, n. 2, July - December 2012

behind the failure of QMS initiatives in US corporate world (KRUMWIEDE, 1998) and their negligent attitude seemed frustrating for those practitioners who involved in implementing this system far and wide in order to bring growth and progress on continuous basis. The general perception of masses with reference to QMS was negative and it has been taken as supplementary pressure with additional demand of documentation, internal audit and training with the help of which government extends its control over people. Quality Assurance, quality testing, quality inspection, quality control and Quality management system was considered as a new way of doing things and practitioners advocated this way with their fullest potential. (RIPPIN, WHITE and MARSH, 1994) Though quality management keeps its origin in mass industrialization for market economy but the overall picture was different from the way it was painted in the beginning. It materialized wherever homogeneous progressions are succeeded by evidences directing at undisputed manufacturing objectives ratified by coherent performers creating knowledgeable selections in unrestricted marketplace. It is thus based on a world view of Positivistic and Epistemology Functionalistic system (JACKSON, 2000; SILVESTRO, 1998).

By ensuring quality assurance optimal improvement in performance can be achieved in an organization (manufacturing or service). The rhetoric of quality is all about empowerment Questionnaire will be sent to 125 respondents out of which 100 responses will be accepted with equal representation of 10 top ranking channels, as recommended by Cohen(1998) and Barckley et al. (1995) the minimum sample size requirement should be ten times largest. Sample size is determined on two bases; about getting employee to own their jobs and to join together in small group to improve every aspect of their work consistently and forever (DEMING, 1982).

Finessing Quality Management into the specific area of media management requires a skill of both counselor and bureaucrat. Taking the pulse of human interaction with in media organization involves the unique challenge of managing the oft autonomous, artful worker .Do all media organizations subscribe to a management system? Lusting for profits is not management, but rather an example of high level, 
Independent Journal of Management \& Production (IJM\&P) ISSN: 2236-269X DOI: 10.14807/ijmp.v3i2.47

v. 3, n. 2, July - December 2012

single issue decision making. True managers are those supervisors who nurture quality realize that there are human persons involved in all processes. Recognizing subordinates as stakeholders allows for the injection of a new idea, the planting of a seed of creativity, or a mutational change potentially cultivate traits within an organization, which can aid in its survival with in the competitive field of media. Encouraging technical writing skills, an incredulous nature, professional training, and a business acumen builds a better journalists.

The market currently defines the media menu. Money is key to content, competition is key to capitalism. If there is no competition, then the market dollars do not work fairly to determine content. Management is indicted with harmonizing these forces. It seems significant important to endorse corporate accountability whereas evading restriction. Conventionally TQM was not supposed to be a considerable factor with respect to those organizations that were involved in creative productionism. Structured media offer facilities, as communications, or perceptible merchandise like newspaper or magazine. Anthropological element's acknowledgment is essential to recognize the interactive abilities desired to accomplish and withstand fruitful modification (WELLINS, 1995)

Number of organizations is in use of paper based report cards for their assessment and evaluation nonetheless numerous journalists discover this in correct intended for a imaginative specialized commotion and appeared frustrated and dejected by the specific QMS terminology used to frame and categorize their creative output. It seems like converting a newsroom into the production floor of a factory, it can be done but the point is that soon after that, the atmosphere would be unworkable for journalists to perform their duties as they will loose creative freedom. (UNDERWOOD, 1998).

The exceptional diminuendos of media has not given an open way in to the quality assurance framework and it has never had been a subject of related interest. \{Submissions in regions wherever certain supposition is not effective have a tendency to be challenging (SEE MORGAN and MUGATROYD, 1994; KIRKPATRICK and LUCIO, 1995; ADAMS, 1998) for instance health care and software engineering; these 
Independent Journal of Management \& Production (IJM\&P) ISSN: 2236-269X DOI: 10.14807/ijmp.v3i2.47

v. 3, n. 2, July - December 2012

are based upon as peculiar, troubleshooting routines, volatile surroundings, and contentious intentions with a possibility of having non market connections\} a handful of researches (OSBORN and FALL, 2000; LILLRANK 2003; JARVENPAA and STAPLES, 2000) have been piloted in this very area nonetheless plentiful has had to be discovered as there lying many branded research studies and quality assurance simulations/structure in academia (at primary, secondary and higher level) Media is as unique as education in many ways both lay in service sector. The substantial differences between educational and commercial organization need careful considerations (SRIKANTHAN and DALRYMPLE,2003) In such a complex system as service sector, the diverse needs of customers and the process of satisfying them could be a major issue(VENKATRAMAN, 2007).

Pakistan is rapidly transforming into an information society due to changing dynamics (basic industries manufacturing and agriculture to fast pace high value information based economy) internationally and influx of latest information technology. The efforts made towards information society should be correlated with strategic planning and cultural heritage of country. According to PEMRA survey conducted in 2005 there were 16400 people shifted from their previously opted field to media and around 15 billion Pak Rs have been invested in a year in this newly emerging media field. These figure exhibit new trends but these new entrants are not properly trained and equipped with the latest tools to work efficiently in this field due to lack of knowledge, lack of skills, lack of confidence, lack of innovation and dependency thinking (AMEN and GORMAN, 2009). This suggests that, in term of benefits to new team and society, we have at least as much to gain from the rapid development of quality assurance.

This study will provide perceptual frame work of quality assurance in media organization and barriers to its implementation in context of Pakistan.

\section{RESEARCH QUESTION}

On the basis of above discussion the following research questions arise; 
Independent Journal of Management \& Production (IJM\&P) ISSN: 2236-269X DOI: 10.14807/ijmp.v3i2.47

v. 3, n. 2, July - December 2012

1. What are the factors that affect Quality Management in media organizations?

2. What are the barriers to the implementation of Quality Management in media organization?

\section{LITERATURE REVIEW}

Over the previous few decades businesses have originated to comprehend that to remain universally competitive, a continuous and comprehensive self-assessment was needed to improve organizational performance cross the board in a holistic manner (CROSBY, 1979; DEMING, 1986; NAVES and NAKHAI, 1993; MELE and COLUCIO, 2006). In this very regard, there are number of gurus who define quality as Crosby (1979) describes quality as conformance to requirement while Juran \& Gryna (1980) explain quality as fitness for use. Deming (1986) as "a predictable degree of uniformity and dependability at low cost and suited to the market is more toward quality in operation. The conventional definition of quality as conformance to standard was not quiet appealing for many organizations and they strive move towards customer focus in order to bring individual mainstream in their processes. In the very beginning organizations kept on working on improving their internal functions and processes and there was a very little understanding with reference to interlink these processes and functions with the ultimate output of the organization that directly links with real customers of the organization (BRIGHAM, 1993). This lag between careful customer focus and organizational processes lead to the resultant failure and pushed companies to struggle fast to come up to the mark. The notion of quality could be more adequate and understandable if expounded in the very right perspective of customer needs and wants linked with organization outcome.

Quality management confines in mass production processes related with market economy The fundamental nursery for quality management has always been the hard core manufacturing processes aiming at market conquerence and gaining leadership through cost minimization. It is therefore grounded on a universal-view of empiricism and functionalized systematic interactions (JACKSON, 2000; SILVESTRO, 1998). 
Independent Journal of Management \& Production (IJM\&P) ISSN: 2236-269X DOI: 10.14807/ijmp.v3i2.47

v. 3, n. 2, July - December 2012

Problems appeared in those areas where these assumptions did not seem valid enough to prove the point (SEE MORGAN and MURGATROYD, 1994; KIRKPATRICK and LUCIO, 1995; ADAMS, 1998). Scoes of services oriented organizations are out of this peculiar procedural interface and which are exposed to a set of individualistic approach in their functions which cannot be generalized. The core difference in these service oriented organization with reference to quality management concepts was the way they worked, in the absence of any well-defined code of operation, a well written document but on man-to-man and case to case basis, their quality parameters were altogether different from an organization working in a controlled atmosphere. The intrinsic source of change was the information as the entire industry was and is in the business of trading information from all the way around. Numerous studies point out that reduced, imperfect, in-efficient or misplaced information is supposed as a furthermost grave quality problem (ENGLISH, 1999; FERGUSON and LIM, 2001; CRUMP, 2002). Huang et al. (1999) underlined that information ought not to be preserved as a simple by-product of countless undertakings nonetheless with the identical significance as merchandises. An apparent methodology is to center on customer desires and due needs.

In industry, finished products are always inspected as a defined protocol of quality -control. The question is how can we frame the finished product with reference to media? Since that in simple words whatever is being produced is the finished product . Though, various scholars have linked production with different forms of services and figured out that even though manufacturing industry and services are poles apart in terms of business processes, number of their interfaces as customer focus, understanding customer requirements, working in dynamic environment are very similar and uni-dimensional (STENSAASEN, 1995; LUNDQUIST, 1998; SRIKANTHAN and DALRYMPLE, 2003). In reply to Kohn (1993), Schmoker and Wilson (1993) have emphasized that by intelligently acclimatizing TQM in the framework of academia, it opens an exceptional chance to flourish wherever additional struggles ought to unsuccessful. In oppose Kohn's explanations, they indicate Total Quality's foundation in sound psychology, its established and confirmed paybacks equally to TV channels and 
Independent Journal of Management \& Production (IJM\&P) ISSN: 2236-269X DOI: 10.14807/ijmp.v3i2.47

v. 3, n. 2, July - December 2012

business and its self-concentrating instrumentation. Lundquist (1998) positions that there are particular outstanding likenesses amid manufacturing and Services - the buyer concentration, procedural alignment and incessant upgrading ideas of TQM approved in industry is very plentifully appropriate in service.

The world of modest atmosphere needs Quality of media. There is absolutely a necessity to accept modification in the, media procedures to progress and stay vigorous in the profession of Media. TQM seems to be a methodical and a rationalized attitude for quality administration and change management (HAMMERSLEY and PINNINGTON, 1999). At the same time, the considerable alterations in the middle of service and marketable establishments want cautious deliberations (SRIKANTHAN and DALRYMPLE, 2003).

\section{Barriers}

As per numerous authorities, Quality Management remains a slightest worldwide prerequisite for remaining in trade as verbalized by variations in culture and marketplace (BRIGHAM, 1993). However, outcomes from Quality Management linked collected works determine that in several cases, Quality Management has futile to harvest guaranteed outcomes (KOCH and FISHER, 1998; BRIGHAM, 1993). Brigham stresses that the studies do not settle that the Quality Management viewpoint is insignificant somewhat proposes that the application of Quality Management has been underprovided or mistaken.

Consequently the principal chief barricade for the submission of Quality Management in edification is the misapprehension of Quality Management attitude and the nonexistence of understanding the processes that are dissimilar in service industry that might be owing to very limited knowledge with reference to quality management; in addition to it the foremost barrier in implementing quality management in letter and spirit is the absence of leadership in manufacturing and services sector (BRIGHAM, 1993) or if ever it was available then the momentum and pace of this leadership was no so absorbant, supportive and vibrant as needed. The possibility of presence of another barricade and it was the fear with regard to the vredibility of quality management as if it 
Independent Journal of Management \& Production (IJM\&P) ISSN: 2236-269X DOI: 10.14807/ijmp.v3i2.47

v. 3, n. 2, July - December 2012

would work they way it has been regarded or not. (SEBASTIANELL and TAMINI, 1998). Another barrier may possibly be workers' confrontation to change in service segment, maximum employees are mostly specialists who by custom assume self-sufficiency and self-determination. Educational worker possibly will not like being requested to change of mind regarding their instruction flairs (BLANKSTEIN, 1996) additionally; it is a mutual certainty that Quality Management enhances needless stratums of administration (SEBASTIANELL and TAMINI, 1998) that is not a favored area amid educational experts.

Pitiable prospectus design might tip to excellence catastrophe. There might be inappropriate educational structures and measures that function as a blockage despite the fact commanding alterations in prospectus or sequence provision (KOHN, 1993). In addition to it, with Quality Management, there might be too plentiful of papers of processes, that chomp time and energy.

An additional blockade might be the absence of adequate reserves and capitals. Quality Management encompasses a standard modification in the attitude of the whole association. This can be attained over and done with methodical and planned drill of all the staffs. Henceforth, Quality Management contains extraordinary budget, energy and stretch (KOCH and FISHER, 1998).

Is all easier when we talk of improvement in characteristics of a product as compared to same in service industry where intangible outcomes are the real outcomes as in services sector the notion of quality revolves around people, delivery time, efficiency which altogether posit a dangerous barricade in terms of auditing the quality parameters (HARVEY, 1995b; YORKE, 1997; OWLIA and ASPINWALL, 1998).

The Quality Assurance outline ought to be constructed upon a conventional set of fundamental standards and notions. These standards and notions deliver the groundwork for assimilating the significant performance necessities inside the quality context. A set of important central standards founding the structure blocks of the planned Quality reassurance context is enumerated as follows; 
Independent Journal of Management \& Production (IJM\&P) ISSN: 2236-269X DOI: 10.14807/ijmp.v3i2.47

v. 3, n. 2, July - December 2012

- Leadership and quality culture.

- Continuous improvement and innovation in processes.

- Employee participation and development.

- Fast response and management of information.

- Customer-driven quality.

- Partnership development, internally and external

Quality circles, a management method rented from Japanese trade is at the moment being measured in advanced teaching surroundings (ROMERO et al., 1995; FREED et al. 2000). A quality circle comprises of a minor cluster of individuals that encounter on a consistent basis, to debate difficulties, pursue solutions, and collaborate with management in the application of those solutions (JURAN and GRYNA, 1980; ISHIKAWA, 1990). Quality circles apply prearranged tactics to problem answering and function on the code that worker contribution in policymaking and problem solving advances the excellence of labor

\section{THEORETICAL FRAMEWORK}

It seems vital as of the collected works that quality assurance guides to organization enactment. The proposition likewise ascertains the involvement of definite blockades as flexible as misinterpretation of QA, deficiency of leadership visualization, nonexistence of self-assurance of receiving wished outcome, QM application is obstructive, QM application drinks considerable interval, privation of enough capitals and possessions, assessment is problematic to determine.

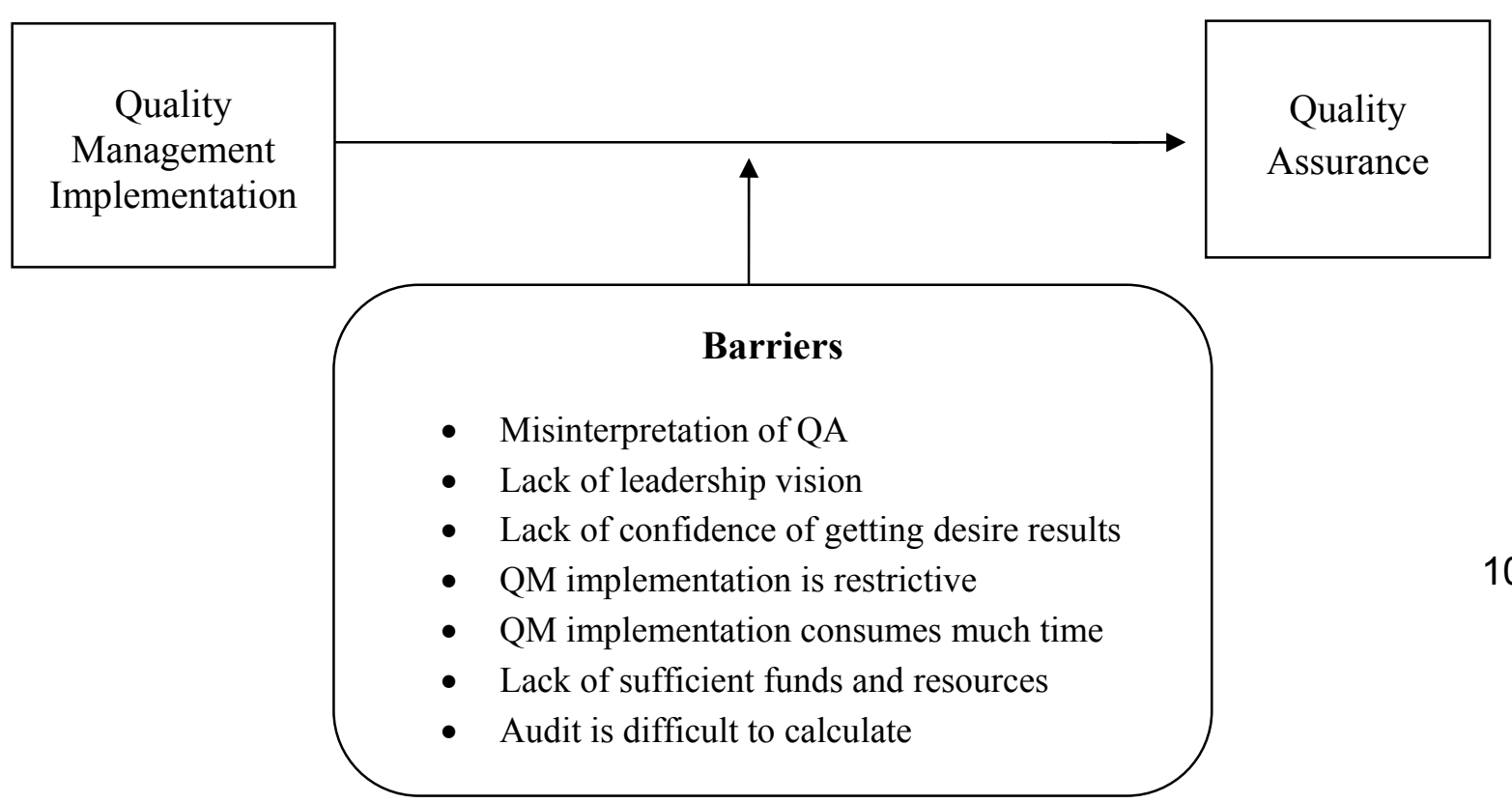


Independent Journal of Management \& Production (IJM\&P) ISSN: 2236-269X DOI: 10.14807/ijmp.v3i2.47

v. 3, n. 2, July - December 2012

In the theoretical model, QM application is reserved as forecaster variable and Quality assurance is occupied as conclusion variable. misinterpretation of QA, deficiency of leadership visualization, nonexistence of self-assurance of receiving wished outcome, QM application is obstructive, QM application drinks considerable interval, privation of enough capitals and possessions, assessment is problematic to determine are taken as moderating variables as per research questions, supported by the literature review.

\section{Hypotheses}

$\mathrm{H}_{1}$ : Lack of necessary knowledge about quality management is the reason of barrier to its implementation.

$\mathrm{H}_{2}$ : Lack of proper strategic leadership vision affects adversely the implementation of QM

$\mathrm{H}_{3}$ : The efforts of implementing QM do not generate desired result.

$\mathrm{H}_{4}$ : QM implementation is restrictive to the established norms of work environment.

$\mathrm{H}_{5}$ : QM implementation consumes much time for unnecessary documentation.

$\mathrm{H}_{6}$ : Lack of sufficient funds and resources is the reason of barrier to it implementation.

$\mathrm{H}_{7}$ : Quality assurance is difficult to calculate through audit

\section{METHODOLOGY}

\section{Research Paradigm}

Henning et al. (2004) describe a paradigm as a theory or hypothesis, a paradigm is somewhat a context inside which theories are constructed, and that basically effects in what way you perceive the world, concludes your perception, and figures your 
Independent Journal of Management \& Production (IJM\&P) ISSN: 2236-269X DOI: 10.14807/ijmp.v3i2.47

v. 3, n. 2, July - December 2012

indulgent of how effects are associated. Possessing a specific world outlook impacts your own conduct, your specialized training, and eventually the place you yield with respect to the topic of your investigation.

The scope of the hypothesis necessitates theoretical description and hypothesis expansion over the deduction method and to gather facts to one or the other falsify the hypothesis or gather the confirmations to upkeep the hypothesis. So the paradigm for this study is Positivism that uses empiricism theory for collection and organization of empirical facts, forming hypothesis, deducing consequences of hypotheses as testable predictions, testing the hypotheses with collected data and finally evaluating the outcome of testing.

\section{Research Type}

The hypotheses depict that the purview of the thesis is explaining the relationship between the variables of interest and their direction; therefore this would be an explanatory study.

\section{Research Strategy}

The basic theme of the research is to find out the relationships among the variables of interests. For this purpose, literature review and hypothesis are developed and will be tested after the data collection and then conclusion will be extracted from the results; therefore the thesis uses deductive approach.

\section{Population}

The population of this study is satellite TV channels of Pakistan. These channels are one of the fastest growing industries of Pakistan and because of its rapid growth it attracts fresh graduates as well as those who are already employed and are seeking for alternative jobs. This study will provide perceptual frame work of quality assurance in media organization and barriers to its implementation in context of country like Pakistan

\section{Sampling Frame}

The sample frame of this study comprises of six top performing news channels in Pakistan. Respondents would be each firm's Chief Executive, Marketing Director, 
Independent Journal of Management \& Production (IJM\&P) ISSN: 2236-269X DOI: 10.14807/ijmp.v3i2.47

v. 3, n. 2, July - December 2012

Executive Producer-News/current affairs, Director Human Resources, Director Information Technology; it would make the size of total respondents as 30 with five from each organization.

\section{Data Collection}

All the respondents were personally contacted by the researcher through visits to their respective organization, they were given the questionnaire and collected back once completely filled. The data collection activity was planned and controlled; even the researcher facilitated all the respondents with respect to the comprehension of any clarity needed to develop in terms to better understand the questions.

Measurement Scale:

Likert's 5-point scale was used to frame the responses against every question, where 1 is the lowest and 5 is the highest denominating variable, keeping 3 in the middle as average.

\section{Statistical Interpretation of Data:}

Q1. How do you rate the level of your understanding regarding Quality Management process?

\begin{tabular}{|c|c|c|c|c|c|c|c|c|c|}
\hline & $\mathrm{N}$ & Range & Minimum & Maximum & Mean & Std. Deviation & Variance & \multicolumn{2}{|c|}{ Skewness } \\
\hline & Statistic & Statistic & Statistic & Statistic & Statistic & Statistic & Statistic & Statistic & Std. Error \\
\hline $\begin{array}{l}\text { VAR00001 } \\
\text { Valid N (listwise) }\end{array}$ & $\begin{array}{l}30 \\
30\end{array}$ & 4.00 & 1.00 & 5.00 & 2.8333 & 1.34121 & 1.799 & .141 & .427 \\
\hline
\end{tabular}

The above table reveals the level of understanding pertaining to quality management system, the said question attempted by all the 30 respondents and the average mean of responses is 2.8333 which seems parallel to the allotted 'average' as per our scale. It proves the first hypothesis that reveals that lack of necessary knowledge acts as a barrier in the implementation of Quality management system. The level of selected respondents required extensive understanding of Quality Management system as they are the ones who would frame the policy guidelines, training protocols developing a quality culture across whole population

Q2. Do you agree that Quality Management practices improves efficiency of the organization? 
Independent Journal of Management \& Production (IJM\&P) ISSN: 2236-269X DOI: 10.14807/ijmp.v3i2.47

v. 3, n. 2, July - December 2012

\begin{tabular}{|c|c|c|c|c|c|c|c|c|c|}
\hline & $\mathrm{N}$ & Range & Minimum & Maximum & Mean & Std. Deviation & Variance & \multicolumn{2}{|c|}{ Skewness } \\
\hline & Statistic & Statistic & Statistic & Statistic & Statistic & Statistic & Statistic & Statistic & Std. Error \\
\hline
\end{tabular}

The above table shows the level of agreement of respondents with reference to the role of quality management system in improving overall efficiency of organization. The average response of 3 matches with the 'average' value of 3 as per our scale, here the average value exhibits the essence of affirmation with reference to quality management system and its impact on the overall efficiency of an organization.

Q3. How do you rate your strategic leadership vision?

\begin{tabular}{|l|c|c|c|c|c|c|c|c|c|}
\hline & $\mathrm{N}$ & Range & Minimum & Maximum & Mean & Std. Deviation & \multicolumn{2}{|l|}{ Variance } & \multicolumn{2}{|c|}{ Skewness } \\
\hline & Statistic & Statistic & Statistic & Statistic & Statistic & Statistic & Statistic & Statistic & Std. Error \\
\hline VAR00003 & 289 & 4.00 & 1.00 & 5.00 & 2.6552 & 1.07822 & 1.163 & .394 & .434 \\
\hline Valid N (listwise) & 289 & & & & & & & \\
\hline
\end{tabular}

The level of responses respecting strategic leadership vision touches the overall mean value of 2.656 which is closer to our 'average' value that was allotted to 3 . The level of respondents does require a highest rating of strategic leadership vision and an average leadership vision seems barricade in the implementation of quality management system across organization in a holistic manner as captioned in second hypothesis.

Q4. Do you agree that strategic leadership vision is essential for progress?

\begin{tabular}{|c|c|c|c|c|c|c|c|c|c|}
\hline & $\mathrm{N}$ & Range & Minimum & Maximum & Mean & Std. Deviation & Variance & \multicolumn{2}{|c|}{ Skewness } \\
\hline & Statistic & Statistic & Statistic & Statistic & Statistic & Statistic & Statistic & Statistic & Std. Error \\
\hline VAR00004 & 30 & 4.00 & 1.00 & 5.00 & 2.9000 & 1.32222 & 1.748 & .004 & .427 \\
\hline Valid N (listwise) & 30 & & & & & & & & \\
\hline
\end{tabular}


Independent Journal of Management \& Production (IJM\&P) ISSN: 2236-269X

DOI: 10.14807/ijmp.v3i2.47

v. 3, n. 2, July - December 2012

significant but they are not developing themselves in the form of organizations but as media agencies which is not a very promising situation.

Q7. Do you agree that strategic leadership vision enable organizations to prepare accordingly?

\begin{tabular}{|l|r|r|r|r|r|r|r|r|r|}
\hline & \multicolumn{1}{|c|}{$\mathrm{N}$} & \multicolumn{1}{c|}{ Range } & \multicolumn{1}{c|}{ Minimum } & Maximum & \multicolumn{1}{c|}{ Mean } & Std. Deviation & Variance & \multicolumn{2}{|c|}{ Skewness } \\
\cline { 2 - 9 } & Statistic & Statistic & Statistic & \multicolumn{1}{c|}{ Statistic } & Statistic & Statistic & Statistic & Statistic & Std. Error \\
\hline VAR00007 & 28 & 4.00 & 1.00 & 5.00 & 3.2857 & 1.27242 & 1.619 & -.351 & .441 \\
Valid N (listwise) & 28 & & & & & & & & \\
\hline
\end{tabular}

The response against this question shows a slight variation from above four questions with reference to strategic leadership vision as the average mean value of responses is 3.285 which is higher than our average value of 3 but less than 4 . It clearly reveals the conceptual trend among respondents as they feel the importance of strategic leadership prepares an organization to adapt any upcoming and incoming changes accordingly; but the overall strength of response seems weak focusing the significant of the question.

Q8. Do you agree that efforts of implementing Quality Management generate desired results?

\begin{tabular}{|l|c|c|c|c|c|c|c|c|c|}
\hline & $\mathrm{N}$ & Range & Minimum & Maximum & Mean & Std. Deviation & Variance & \multicolumn{2}{|c|}{ Skewness } \\
\cline { 2 - 9 } & Statistic & Statistic & Statistic & Statistic & Statistic & Statistic & Statistic & Statistic & Std. Error \\
\hline VAR00008 & 299 & 32.00 & 1.00 & 33.00 & 4.5517 & 6.70067 & 44.899 & 3.703 & .434 \\
Valid N (listwise) & 299 & & & & & & & & \\
\hline
\end{tabular}

The response against this questions shows 4.55 average mean score which is very close to the 'highest' category with 5 score and it exhibits the confidence of respondents in uni-dimensional effort towards implementing quality management system that generates desired results and established hypothesis covering this question stands rejected as most number of respondents are in strong agreement with reference to the effect of efforts, but the point is that their inclination does not qualify their response as in previous questions the average response reveals that they are not very enthusiastic in establishing a concrete ground needed for implementing quality management system. 
Independent Journal of Management \& Production (IJM\&P) ISSN: 2236-269X DOI: 10.14807/ijmp.v3i2.47

v. 3, n. 2, July - December 2012

Q9. Do you agree that Quality Management is norm based? (Non flexible)

\begin{tabular}{|l|r|r|r|r|r|r|r|r|r|}
\hline & \multicolumn{1}{|c|}{$\mathrm{N}$} & \multicolumn{1}{c|}{ Range } & Minimum & Maximum & \multicolumn{1}{c|}{ Mean } & Std. Deviation & Variance & \multicolumn{2}{|c|}{ Skewness } \\
\cline { 2 - 9 } & Statistic & Statistic & \multicolumn{1}{c|}{ Statistic } & \multicolumn{1}{c|}{ Statistic } & Statistic & \multicolumn{1}{c|}{ Statistic } & Statistic & Statistic & Std. Error \\
\hline VAR00009 & 29 & 4.00 & 1.00 & 5.00 & 2.6897 & 1.16813 & 1.365 & .516 & .434 \\
Valid N (listwise) & 29 & & & & & & & & \\
\hline
\end{tabular}

Average mean value of the responses collected to counter this question is 3.13 which matches the given 3 against average of responses that exemplify that the approach of the respondents towards implementation of quality management system is apparently restricted to established norms at the work place. This response reveals the power of overall organization design and culture that plays a pivotal role in every such practice that links with the behavior and norms of an organization and if norms are not change supported then desired results cannot be ascertained.

Q10. How do you rate time consumed in Quality Management implementation?

\begin{tabular}{|l|r|r|r|r|r|r|r|r|r|}
\hline & \multicolumn{1}{|c|}{$\mathrm{N}$} & Range & Minimum & Maximum & Mean & Std. Deviation & Variance & \multicolumn{2}{c|}{ Skewness } \\
\cline { 2 - 9 } & Statistic & Statistic & Statistic & Statistic & Statistic & Statistic & Statistic & Statistic & Std. Error \\
\hline VAR00010 & 28 & 4.00 & 1.00 & 5.00 & 3.0714 & 1.21499 & 1.476 & .255 & .441 \\
Valid N (listwise) & 28 & & & & & & & & \\
\hline
\end{tabular}

Average mean value of 3.07 obtained against this question relevant to fifth hypothesis as the respondents are of the opinion that the documentation of quality management system consumes unnecessary time. There are two dimensions of this response as the time consumed when the documentation process is under way and after implementation when time is required to maintain the records and keep them intact to review and revise the processes in the light of these records. The overall perception of the participants appear negative as they feel it as an extra burden on them.

Q11. How do you rate documentation in Quality Management implementation? 
Independent Journal of Management \& Production (IJM\&P) ISSN: 2236-269X DOI: 10.14807/ijmp.v3i2.47

v. 3, n. 2, July - December 2012

\begin{tabular}{|c|c|c|c|c|c|c|c|c|c|}
\hline & $\mathrm{N}$ & Range & Minimum & Maximum & Mean & Std. Deviation & Variance & \multicolumn{2}{|c|}{ Skewness } \\
\hline & Statistic & Statistic & Statistic & Statistic & Statistic & Statistic & Statistic & Statistic & Std. Error \\
\hline $\begin{array}{l}\text { VAR00011 } \\
\text { Valid N (listwise) }\end{array}$ & $\begin{array}{l}29 \\
29\end{array}$ & 4.00 & 1.00 & 5.00 & 2.6897 & 1.16813 & 1.365 & .516 & .434 \\
\hline
\end{tabular}

The role of documents in quality management system has been rated at the average mean value of 2.68 that is near to our average of 3 which shows that respondents consider the importance of documentation with reference to time as average and it shows their commitment towards the process of documentation which is the key in QM implementation

Q12. How do you rate funds required in Quality Management?

\begin{tabular}{|l|r|r|r|r|r|r|r|r|r|}
\hline & \multicolumn{1}{|c|}{$\mathrm{N}$} & Range & Minimum & Maximum & Mean & Std. Deviation & \multicolumn{2}{|c|}{ Variance } & \multicolumn{2}{c|}{ Skewness } \\
\cline { 2 - 9 } & Statistic & Statistic & Statistic & Statistic & Statistic & Statistic & Statistic & Statistic & Std. Error \\
\hline VAR00014 & 30 & 4.00 & 1.00 & 5.00 & 3.3333 & 1.34762 & 1.816 & -.299 & .427 \\
Valid N (listwise) & 30 & & & & & & & & \\
\hline
\end{tabular}

Healthy average mean of 3.33 appears against this question which shows the response above our average of 3 that supports the corresponding hypothesis that lack of funds area barrier in implementation of quality management system.

Q13. How do you rate resources required in Quality Management?

\begin{tabular}{|c|c|c|c|c|c|c|c|c|c|}
\hline & $\mathrm{N}$ & Range & Minimum & Maximum & Mean & Std. Deviation & Variance & \multicolumn{2}{|c|}{ Skewness } \\
\hline & Statistic & Statistic & Statistic & Statistic & Statistic & Statistic & Statistic & Statistic & Std. Error \\
\hline $\begin{array}{l}\text { VAR00012 } \\
\text { Valid N (listwise) }\end{array}$ & $\begin{array}{l}30 \\
30\end{array}$ & 4.00 & 1.00 & 5.00 & 3.4333 & 1.16511 & 1.357 & -.528 & .427 \\
\hline
\end{tabular}

The role of human, financial and other resources are so important in the implementation of quality management system is so important and above average response of 3.433 shows that respondents are well aware of this fact that without ample and adequate resources, effective implementation of QMS is not possible; and most of the time the question of funds act as the most focused barricade in this very process.

Q13. Do you agree that performance of Quality Management system is difficult to calculate through audit? 
Independent Journal of Management \& Production (IJM\&P) ISSN: 2236-269X DOI: 10.14807/ijmp.v3i2.47 v. 3, n. 2, July - December 2012

\begin{tabular}{|c|c|c|c|c|c|c|c|c|c|}
\hline & $\mathrm{N}$ & Range & Minimum & Maximum & Mean & Std. Deviation & Variance & \multicolumn{2}{|c|}{ Skewness } \\
\hline & Statistic & Statistic & Statistic & Statistic & Statistic & Statistic & Statistic & Statistic & Std. Error \\
\hline $\begin{array}{l}\text { VAR00013 } \\
\text { Valid N (listwise) }\end{array}$ & $\begin{array}{l}29 \\
29\end{array}$ & 4.00 & 1.00 & 5.00 & 3.0690 & 1.13172 & 1.281 & -.144 & .434 \\
\hline
\end{tabular}

Overall perception of respondents touches the average mean value of 3.0 that matches our average value also as they are of the opinion that quality management system cannot be judged through audit; it is again a misconception which directs towards the very first hypothesis as the awareness of QMS is very low among top management that is why they cannot perceive the internal audit activity that encircle whole QMS in a very impartial, quantitative and concrete manner.

\section{CONCLUSION:}

There are grave misconception and ambiguities when we discuss QMS, especially in services sector as media etc., and it is the core reason that in Pakistan there is no such concept of implementing QMS and being benefitted with this implementation in media organizations. Our study opens the doors towards the need of creating awareness among the top brass of media organizations that is needed to have strong, lasting and concrete steps towards its implementation in a comprehensive manner.

\section{REFERENCES}

ADAMS, R. (1998), Quality Social Work, Macmillan, London.

BLANKSTEIN, A.M. (1996), "Why TQM can't work - and a school where it did", Education Digest, v. 62 n. 1, p. 27-30.

BRIGHAM, S. E. (1993), "Lessons we can learn from industry", Change, v. 25 n. 3, p. 42-7

CROSBY, P. B. (1979), Quality Is Free, McGraw-Hill, New York, NY

CRUMP, N. (2002), "Managing professional integration in an acute hospital - a sociopolitical analysis", The International Journal of Public Sector Management, V. 15 N. 2, p. 107-17.

DAVENPORT, T. H.; PRUSAK, L. (1998), Working Knowledge - How Organizations Manage What They Know, Harvard Business School Press, Boston, MA.

DEMING, W. E. (1982), Out of the Crisis, Cambridge University Press, Cambridge. 
Independent Journal of Management \& Production (IJM\&P) ISSN: 2236-269X DOI: 10.14807/ijmp.v3i2.47

v. 3, n. 2, July - December 2012

DEMING, W. E. (1986), Out of Crisis, Cambridge University Press, Cambridge

English, L.P. (1999), Improving Data Warehouse and Business Information Quality, Wiley, New York, NY.

FERGUSON, B.; LIM, J. N. W. (2001), "Incentives and clinical governance - money following quality?", Journal of Management in Medicine, V. 15, p. 453-87.

HUANG, K. T.; LEE, Y. W.; WANG, R. Y. (1999), Quality Information and Knowledge, Prentice-Hall, New York, NY.

HARVEY, L. (1995b), "Beyond TQM", Quality in Higher Education, V. 1 N. 2, p. 123-46

JURAN, J. M.; GODFREY, A. B. (1999), Juran's Quality Handbook, 5th ed., McGrawHill, New York, NY.

JACKSON, M. C. (2000), Systems Approaches to Management, Kluwer, New York, NY.

KRUMWIEDE, D. W.; AHEU, C.; LAVELLE, J (1998). Understanding the relation of top management personality to TQM implementation. Production \& Inventory Management Journal v. 39, n. 2, p. 6-10

KIRKPATRICK, I.; LUCIO, M. M. (Eds) (1995), The Politics of Quality in the Public Sector, Routledge, London.

KOHN, A. (1993), "Turning learning into a business: concerns about total quality", Educational Leadership, V. 51 N. 1, p. 58-61

KANWAL AMEEN, G. E. Gorman, (2009),"Information and digital literacy: a stumbling block to development?: A Pakistan perspective", Library Management, V. 30, n.1, p. 99 $-112$

$\mathrm{KOCH}$, J. V.; FISHER, J. L. (1998), "Higher education and total quality management", Total Quality Management, V. 9 N. 8, p. 659-68.

LUNDQUIST, R. (1998), "Quality improvements of teaching and learning in higher education: a comparison with developments in industrial settings", Teaching in Higher Education, $\quad$ V. 3 N. 1, p. 51-62.

MORGAN, C.; MURGATROYD, S. (1994), Total Quality Management in the Public Sector, Open University Press, Buckingham.

MELE, C.; COLUCIO, M. (2006), "The evolving path of TQM: towards business excellence and stakeholder value", International Journal of Quality \& Reliability Management, V. 23

NONAKA, I.; TAKEUCHI, H. (1995), The Knowledge-creating Company, Oxford University Press, New York, NY.

NEVES, J. S.; NAKHAI, B. (1993), "The Baldrige award framework for teaching total quality management", Journal of Education for Business, V. 69 N. 2, p. 121-5

OWLIA, M. S.; ASPINWALL, E. M. (1998), "A framework for measuring quality in engineering education”, Total Quality Management, V. 9 N. 6, p. 501-18. 
Independent Journal of Management \& Production (IJM\&P) ISSN: 2236-269X DOI: 10.14807/ijmp.v3i2.47

v. 3, n. 2, July - December 2012

PAUL LILLRANK, (2003),"The quality of information", International Journal of Quality \& Reliability Management, V. 20 Iss: 6 p. 691 - 703

SRIKANTHAN, G.; DALRYMPLE, J. (2003), "Developing alternative perspectives for quality in higher education", International Journal of Educational Management, V. $17 \mathrm{~N}$. 3, p. 126-36.

SITALAKSHMI VENKATRAMAN, (2007),"A framework for implementing TQM in higher education programs", Quality Assurance in Education, V. 15 Iss: 1 p. 92 - 112

SEBASTIANELL, R.; TAMINI, N. (1998), "Barriers of TQM: a class-level student project", Journal of Education of Business, V. 73 N. 3, p. 158-62.

SCHMOKER, M.; WILSON, R.B. (1993), “Adapting total quality doesn't mean turning learning into a business", Educational Leadership, V. 51 N. 1, p. 62-3.

SILVESTRO, R. (1998), "The manufacturing TQM and service quality literatures: synergistic or conflicting paradigms?", International Journal of Quality \& Reliability Management, V. $\quad 15$, N. 3, p. 303-28.

STENSAASEN, S. (1995), "The application of Deming's theory of total quality management to achieve continuous improvements in education", Total Quality Management, V. 6

TOZER, G. (1999), Metadata Management for Information Control and Business Success, Artech House, Norwood, MA.

UNDERWOOD, D (1998,July/August). Assembly-line journalism. Columbia Journalism Review, 4.

WELLINS, R.; RICK, S. (1995,October 19) Taking account of human factor. People Management, $\quad 1(21), 30-3$

WANG, R. Y.; LEE, Y. W.; PIPINO, L. L.; STRONG, D. M. (1998), "Manage your information as a product", Sloan Mangement Review, V. 39 N. 4, p. 95-105.

YORKE, M. (1997), "The elusive quarry: total quality in higher education", Tertiary Education and Management, V. 3 N. 2, p. 145-56 